\title{
TWO-PHASE PRESSURE DROP OF REFRIGERANTS DURING FLOW BOILING IN SMALL CHANNELS: AN EXPERIMENTAL INVESTIGATION AND CORRELATION DEVELOPMENT*
}

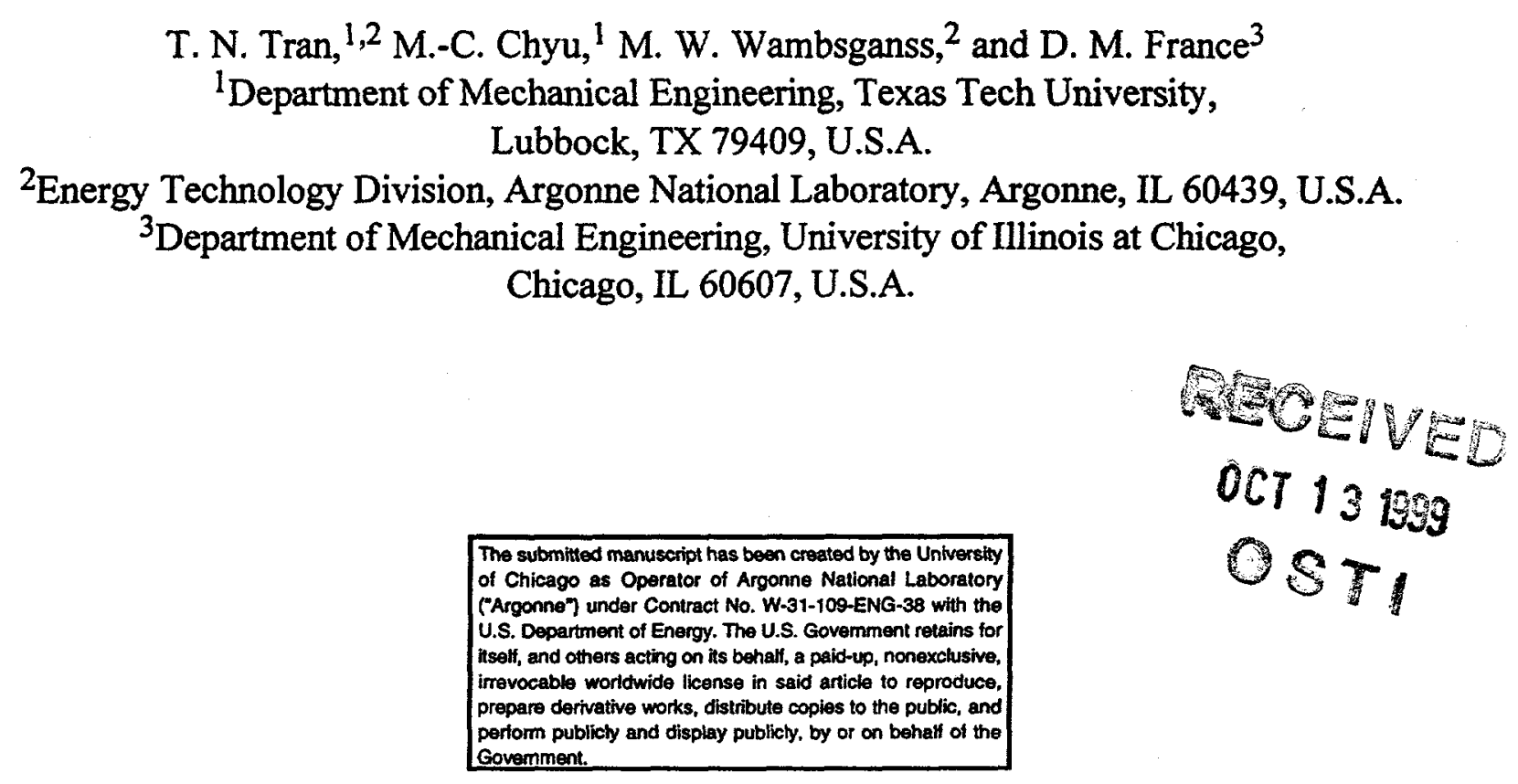

Submitted to Int. Conf. on Compact Heat Exchangers and Enhancement Technology for the Process Industries, Banff, Canada, July 18-23, 1999.

*Work supported by the U.S. Department of Energy, Office of Energy Efficiency and Renewable Energy, Office of Industrial Technologies, under Contract W-31-109-Eng-38. 


\section{DISCLAIMER}

This report was prepared as an account of work sponsored by an agency of the United States Government. Neither the United States Government nor any agency thereof, nor any of their employees, make any warranty, express or implied, or assumes any legal liability or responsibility for the accuracy, completeness, or usefulness of any information, apparatus, product, or process disclosed, or represents that its use would not infringe privately owned rights. Reference herein to any specific commercial product, process, or service by trade name, trademark, manufacturer, or otherwise does not necessarily constitute or imply its endorsement, recommendation, or favoring by the United States Government or any agency thereof. The views and opinions of authors expressed herein do not necessarily state or reflect those of the United States Government or any agency thereof. 


\section{DISCLAIMER}

Portions of this document may be illegible in electronic image products. Images are produced from the best available original document. 


\title{
TWO-PHASE PRESSURE DROP OF REFRIGERANTS DURING FLOW BOILING IN SMALL CHANNELS: AN EXPERIMENTAL INVESTIGATION AND CORRELATION DEVELOPMENT
}

\author{
T. N. Tran, ${ }^{1,2}$ M.-C. Chyu, ${ }^{1}$ M. W. Wambsganss, ${ }^{2}$ and D. M. France ${ }^{3}$ \\ ${ }^{1}$ Department of Mechanical Engineering, Texas Tech University, \\ Lubbock, TX 79409, U.S.A. \\ ${ }^{2}$ Energy Technology Division, Argonne National Laboratory, Argonne, IL 60439, U.S.A. \\ ${ }^{3}$ Department of Mechanical Engineering, University of Illinois at Chicago, \\ Chicago, IL 60607, U.S.A.
}

\begin{abstract}
Two-phase flow pressure drop measurements were made during a phase-change heat transfer process with three refrigerants (R-134a, R-12, and R-113) at six different pressures ranging from $138 \mathrm{kPa}$ to $856 \mathrm{kPa}$, and in two sizes of round tubes $(2.46 \mathrm{~mm}$ and $2.92 \mathrm{~mm}$ inside diameters) and one rectangular channel $(4.06 \times 1.7 \mathrm{~mm})$. State-of-the-art large-tube correlations failed to satisfactorily predict the experimental data. The data were used to develop a new correlation for two-phase pressure drop during flow boiling in small channels. The correlation was then tested against the experimental data for the three refrigerants; the error was $\pm 20 \%$.
\end{abstract}

\section{INTRODUCTION}

Only a few studies in the literature report on two-phase fluid flow and heat transfer in compact heat exchangers. Nevertheless, extensive applications exist in the process industries, where phase-change heat transfer allows more compact heat exchanger designs with better performance than those used for single-phase operation. To further the application of compact heat exchangers in the process industries, there is a need to understand the fundamental issues of two-phase flow and heat transfer in small channels representative of compact heat exchanger flow passages.

In the refrigeration/air conditioning industry, including automobile environment control, a fundamental understanding of multiphase-flow and heat transfer involving boiling and condensing of refrigerants in small channels is important. In particular, there is a need for a validated design correlation for two-phase pressure drop that will facilitate the design and optimization of compact heat exchangers for use with refrigerants.

Jung and Radermacher (1989) conducted experiments with refrigerants R-22, R-114, R-12, and R-152, and refrigerant mixtures in 4-m long, 9.1-mm-inside-diameter, stainless steel tubes. They proposed a correlation for a two-phase flow total pressure drop of pure and mixed refrigerants. In their correlation, the two-phase multiplier is expressed as a function of quality and reduced pressure.

Souza and Pimenta (1995), following their work in 1992 (Souza et al. 1992), tested refrigerants R-134a, R-12, R-22, MP-39, and R-32/125 in a copper tube with two sections; one had an inside diameter (ID) of $7.75 \mathrm{~mm}$, and the other an ID of $10.92 \mathrm{~mm}$. They proposed a 
semi-empirical correlation to calculate the two-phase flow multiplier for pure and mixed refrigerants.

Two-phase flow pressure drop and evaporation heat transfer of refrigerants in small channels have been studied at Argonne National Laboratory (Wambsganss et al. 1993, 1994; Tran et al. 1996), and a correlation for nucleate flow boiling has been reported (Tran et al. 1997). In the Argonne study, two smooth circular tubes and one rectangular channel with hydraulic diameters of $2.46 \mathrm{~mm}, 2.92 \mathrm{~mm}$, and $2.40 \mathrm{~mm}$, respectively were used to simulate flow passages typical of plate-fin heat exchangers. One of the objectives of the study was to determine if largetube correlations can be used to predict two-phase pressure drop of refrigerants in small channels, with hydraulic diameter of about $3 \mathrm{~mm}$, and, as necessary, to develop an experimentally validated predictive method that can facilitate the design and optimization of compact heat exchangers for refrigerants, including those that are environmentally acceptable. The results of the experimental investigation and correlation evaluation/development are presented in this paper.

\section{EXPERIMENTS}

The test apparatus, instrumentation, test procedures, and data reduction methodology, have been presented in detail by Tran et al. (1997). Three different refrigerants were tested in four different channels, as summarized in Table 1.

Single-phase tests were performed to validate the instrumentation and data reduction method (Tran 1998), then two-phase flow pressure drop tests were performed with R-134a at four different averaged pressures of $356,441,634$, and $835 \mathrm{kPa}$; with $\mathrm{R}-12$ at the two averaged pressures of 517 and $824 \mathrm{kPa}$; and with R-113 at an averaged pressure of $169 \mathrm{kPa}$. The accuracy of the data base was assessed by an uncertainty analysis based on the method of sequential perturbations (Moffat 1988; Holman and Gajda 1978). This method allows estimation of an overall uncertainty of a set of data by integrating the uncertainty of each source of error into the data base independently, then using a root sum square method to calculate the overall uncertainty. The uncertainty analysis was incorporated into the spreadsheet program, and an uncertainty was calculated for every test run of each data set. The uncertainty in the measurement of the pressure drop was found to be $\pm 10 \%$.

The total two-phase flow pressure drop consists of two components: an acceleration component and a frictional component. The accelerational pressure drop component results from acceleration of the flow during the evaporation process. It was evaluated and shown to be small relative to the frictional component. Therefore, the measured two-phase pressure drop data was assumed to be representative of the frictional component. 
Table 1. Summary of data for two-phase flow pressure drop test

\begin{tabular}{lcccc}
\hline \multirow{2}{*}{ Parameter } & $1^{\mathrm{a}}$ & $2^{\mathrm{b}}$ & $3^{\mathrm{b}}$ & $4^{\mathrm{c}}$ \\
\cline { 2 - 5 } & $\mathrm{R}-113$ & $\mathrm{R}-12$ & $\mathrm{R}-12$ & $\mathrm{R}-134 \mathrm{a}$ \\
\hline Refrigerant & Stainless steel & Brass & Brass & Brass \\
Channel Material & Circular & Circular & Rectangular & Circular \\
Channel Geometry & 2.92 & 2.46 & 2.40 & 2.46 \\
$\mathrm{D}_{\mathrm{h}}(\mathrm{mm})$ & & & $(1.70 \times 4.06)$ & \\
Total Length (mm) & 412 & 914 & 881 & 914 \\
$\mathrm{P}_{\mathrm{r}}$ & $0.04-0.058$ & $0.12-0.21$ & $0.18-0.23$ & $0.08-0.21$ \\
$\mathrm{G}\left(\mathrm{kg} / \mathrm{m}^{2} \mathrm{~s}\right)$ & $50-400$ & $63-832$ & $44-505$ & $33-502$ \\
q" (kW/m $\left.{ }^{2}\right)$ & $8.8-90.8$ & $7.5-59.5$ & $7.7-129$ & $2.2-49.8$ \\
Exit Quality, $\mathrm{x}$ & $0.02-0.95$ & $0.21-0.94$ & $0.22-0.82$ & $0.24-0.90$ \\
No. of Data Points & 39 & 137 & 132 & 302 \\
\hline
\end{tabular}

aWambsganss et al. (1993).

b Tran et al. (1996).

cTran (1998).

\section{EXPERIMENTAL RESULTS}

For a given refrigerant and test channel, the range of test conditions and the number of test data points are given in Table 1. For all tests, the flow entered the test section in a subcooled condition, and the starting point of saturated boiling ranged from 0.2 to $0.5 \mathrm{~mm}$ downstream of the first pressure port location. Because the pressure drop over the subcooled length is negligibly small, the pressure drop measured by the differential pressure transducer was that of the saturated flow boiling section. Exit quality varied from test to test. The experimental pressure drop data were plotted against exit quality for the averaged pressure of the particular test series and various values of mass flux. 


\section{Refrigerant R-134a}

In Fig. 1, the experimental pressure drop data for tests with R-134a are plotted against exit quality for various values of mass flux and a saturation pressure of $835 \mathrm{kPa}$. The results show that the two-phase flow pressure drop increases as the exit quality increases, as well as increases with mass flux; these trends agree with those of a large tube.

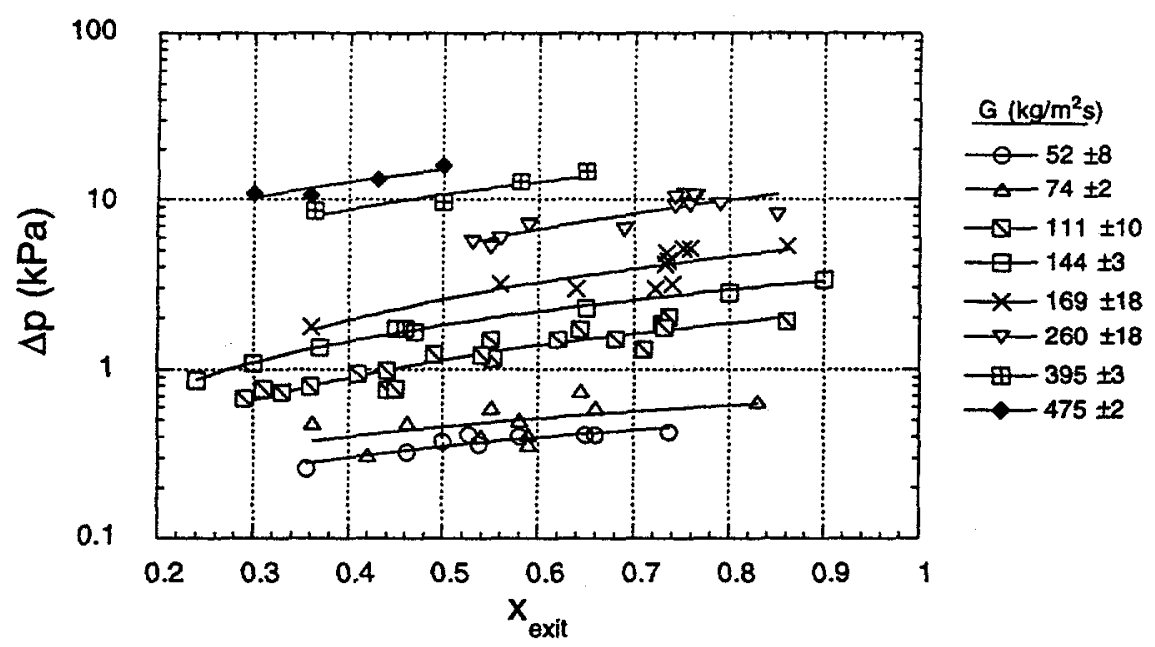

Fig. 1. Pressure drop of $\mathrm{R}-134 \mathrm{a}$ at $\mathrm{p}_{\text {avg }}=835 \mathrm{kPa}$ as a function of exit quality at various values of mass flux

The pressure effect on two-phase flow pressure drop was also investigated. A typical result is shown in Fig. 2, where two-phase flow pressure drop is higher at a lower saturation pressure. This is reasonable because at a lower pressure (lower saturation temperature), the fluid has a higher viscosity and a higher density than it has at a higher pressure. Also, the ratio of liquid to vapor density increases at lower reduced pressure. For R-134a, a decrease in saturation pressure of $47 \%$ causes an increase in two-phase flow pressure drop of about $60 \%$. This pressure effect is also in agreement with large-tube results.

In an attempt to compare the pressure drop data of R-134a in the present study to that of a large tube, the present data were compared to the test results that Eckels et al. (1994) obtained for R-134a in a large smooth tube with an ID of $8 \mathrm{~mm}$ and a test section length of $3.6 \mathrm{~m}$. Due to the difference in the test section length, the comparison is based on pressure gradient instead of pressure drop. The comparison shows that at a saturation pressure of $350 \mathrm{kPa}$, mass flux of 307 $\pm 50 \mathrm{~kg} / \mathrm{m}^{2} \mathrm{~s}$, and a quality range of $0.68 \pm 0.07$ (the closest available quality range compared to the $0.82 \pm 0.05$ in Eckels et al. [1994]), the pressure gradient in the present small-channel study is about 3.3 times higher than that of the large-tube data. It is noteworthy that in their pressure drop tests, the inlet quality varied from 7 to $11 \%$, while in the present study, the inlet quality was $<1 \%$. The Eckels et al. tube diameter was approximately three times that of the tube used in the present study. 


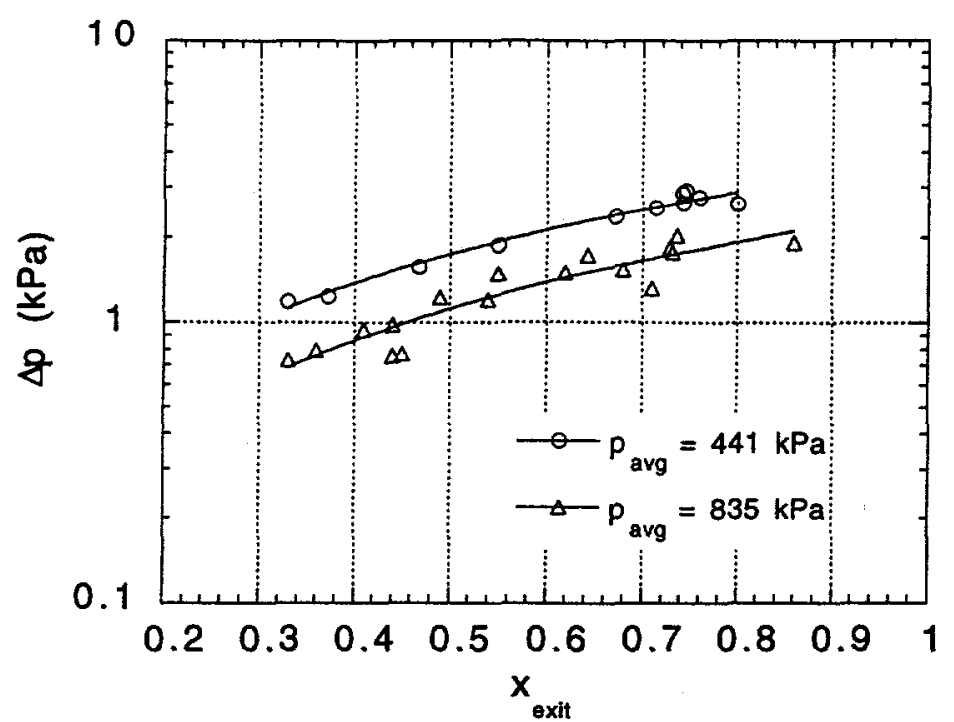

Fig 2. Pressure effect on two-phase flow pressure drop of R-134a at $\mathrm{p}_{\mathrm{avg}}=$ $441 \mathrm{kPa}$ and $835 \mathrm{kPa}$ for $\mathrm{G}=106 \pm 14 \mathrm{~kg} / \mathrm{m}^{2} \mathrm{~s}$

\section{Refrigerant R-12}

The experimental two-phase pressure drop data for R-12 at $824 \mathrm{kPa}$ are shown in Fig. 3 as a function of quality for various values of mass flux. Trends are similar to those of R-134a shown in Fig. 1. In Fig. 4, pressure drop data were plotted against quality at 517 and $824 \mathrm{kPa}$ for the same mass flux of $259 \pm 18 \mathrm{~kg} / \mathrm{m}^{2} \mathrm{~s}$. Figure 4 shows that the two-phase flow pressure drop is higher at a lower saturation pressure. This result agrees with that of R-134a (see Fig. 2). Figure 4 also shows that for R-12 tested in the present study, a decrease in saturation pressure of $37 \%$ causes an increase in two-phase flow pressure drop of about $70 \%$.

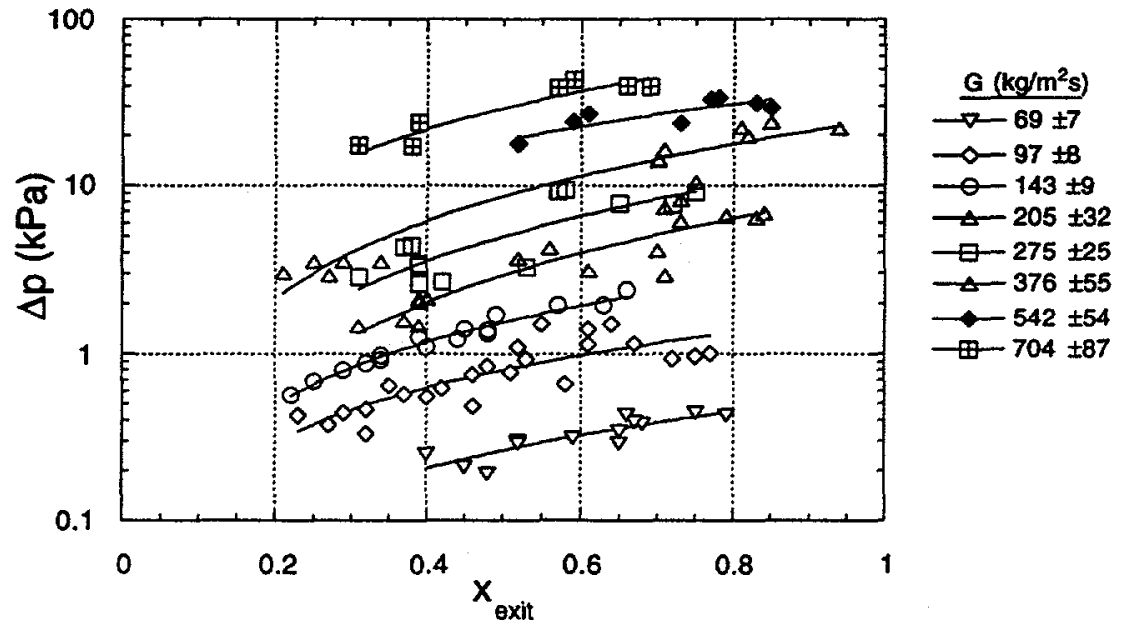

Fig. 3. Pressure drop of R-12 at $\mathrm{p}_{\mathrm{avg}}=824 \mathrm{kPa}$ as a function of exit quality at various values of mass flux 


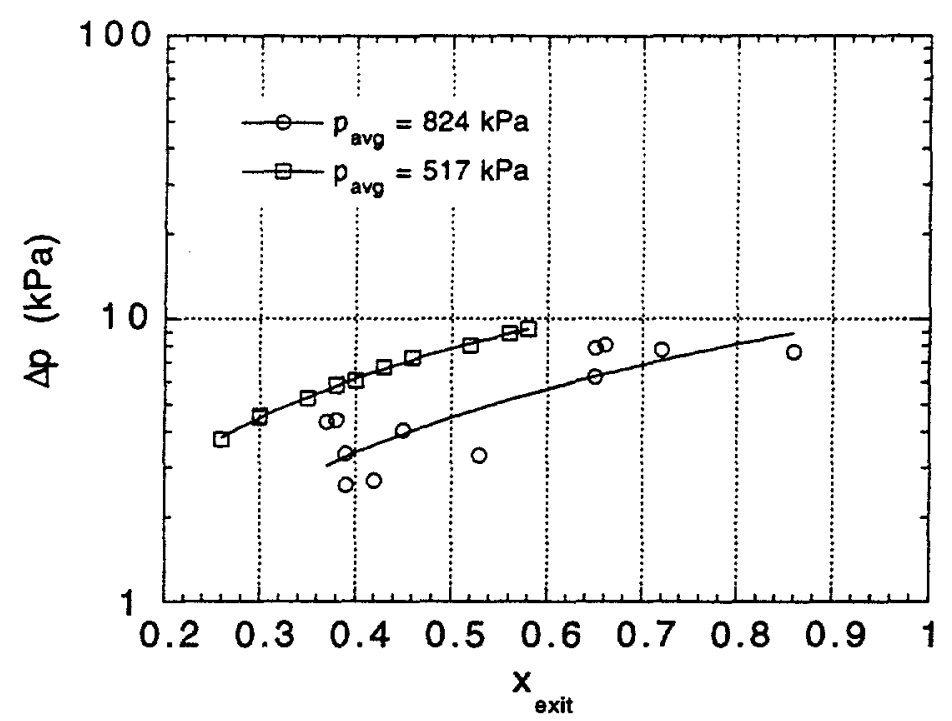

Fig. 4. Pressure effect on two-phase flow pressure drop of $\mathrm{R}-12$ at $\mathrm{p}_{\mathrm{avg}}=517 \mathrm{kPa}$ and $\mathrm{p}_{\mathrm{avg}}=824 \mathrm{kPa}$ for $\mathrm{G}=259 \pm 18 \mathrm{~kg} / \mathrm{m}^{2} \mathrm{~s}$ and $\mathrm{x}_{\text {exit }}=0.58 \pm 0.28$

\section{Comparison of R-134a and R-12}

Refrigerant R-134a is a replacement for R-12 in the refrigeration and air conditioning industry. Therefore, it is of interest and useful to compare the performance of these two refrigerants in terms of pressure drop. Such information is useful to designers in the selection of the appropriate parameters to use with refrigerant R-134a in the design of a new system, or in retrofitting an existing $\mathrm{R}-12$ refrigeration system.

Because both R-134a and R-12 were tested in the same test section under similar test conditions, a direct comparison of two-phase flow pressure drop can be made. Knowing that two-phase flow pressure drop is a function of saturation pressure, exit quality, and mass flux, the comparison can be made based on either the same mass flux or the same heating rate, as suggested by Eckels and Pate (1991). Comparison based on the same heating rate was suggested because $\mathrm{R}-134 \mathrm{a}$ has a higher latent heat of vaporization than that of $\mathrm{R}-12$, and also because a design is often based on a specified heating or cooling rate.

We compared the pressure drop data of R-134a and R-12 in terms of mass flux for a saturation pressure of $835 \mathrm{kPa}$ and a quality of $0.7 \pm 0.05$ (Fig. 5). The results show the same trend reported by Eckels and Pate (1991) for a large tube of $8 \mathrm{~mm}$ dia. and $3.67 \mathrm{~m}$ length, tested at a saturation pressure of $\approx 350$ to $490 \mathrm{kPa}\left(\approx 5-15^{\circ} \mathrm{C}\right.$ saturation temperature). Figure 5 shows that the two-phase flow pressure drop of R-134a is up to $31 \%$ higher than that of R-12 for a range of mass flux from 60 to $300 \mathrm{~kg} / \mathrm{m}^{2} \mathrm{~s}$ and a quality of $0.7 \pm 0.05$. This result is comparable to the difference in pressure drop of up to 50\% reported by Eckels and Pate (1991) for a range of mass flux from 125 to $400 \mathrm{~kg} / \mathrm{m}^{2} \mathrm{~s}$ at a quality of 0.80 to 0.88 . Again, the tube used by Eckels and Pate was more than three times larger in diameter, and the quality was higher and the saturation pressure was much lower, than those of the present study. 


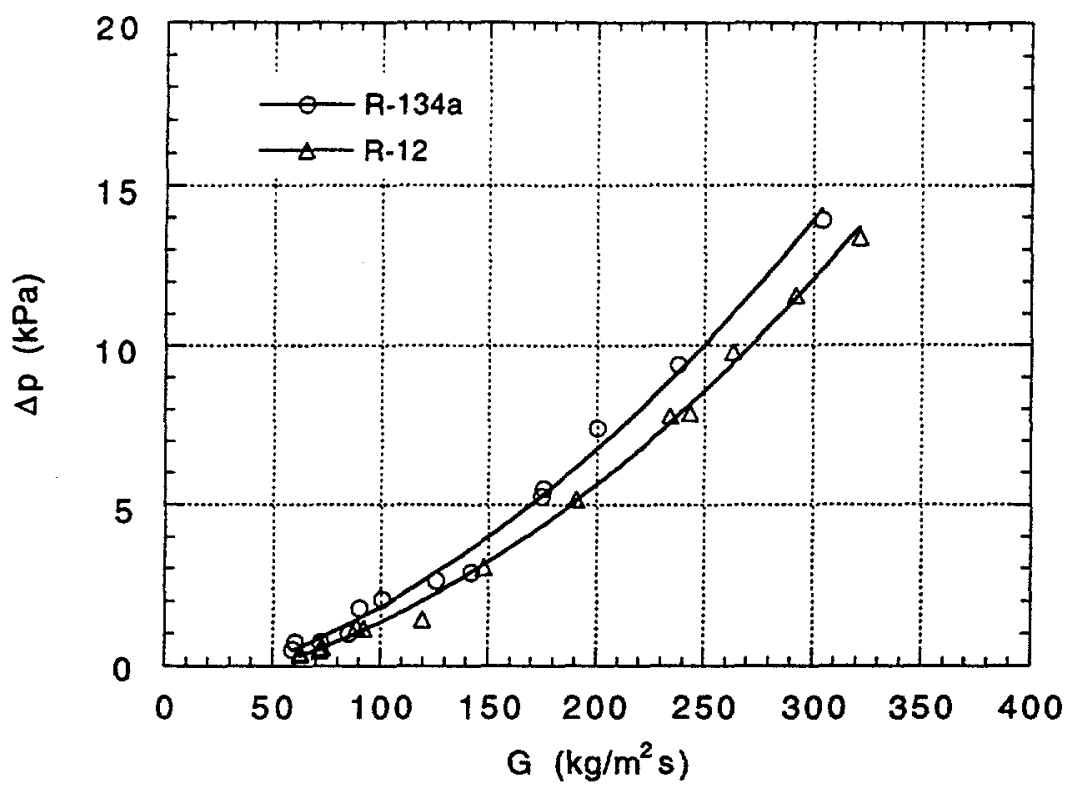

Fig. 5. Comparison of two-phase flow pressure drop between R-134a and $\mathrm{R}-12$ in terms of mass flux for $\mathrm{x}_{\mathrm{exit}}=0.7 \pm 0.05$ and $\mathrm{p}_{\mathrm{avg}}=835 \mathrm{kPa}$

Figure 6 presents the comparison of pressure drop in terms of heat flux, at the quality of $0.7 \pm 0.05$. This comparison indicates that for a given heating rate, the two-phase flow pressure drop of R-134a is 31 to $44 \%$ lower than that of R-12 for the range of heat flux from 5 to $31 \mathrm{~kW} / \mathrm{m}^{2}$. This result is comparable with that reported by Eckels and Pate (1991) for a large tube, where the pressure drop of R-134a was 10 to $30 \%$ lower than that of R-12 for the same heat capacity. Again, the difference from Eckels and Pate's result is due to the much smaller tube, the lower quality, and the higher saturation pressure of the present study. The lower pressure drop of R-134a compared to that of R-12 in Fig. 6 is seen because a lower mass flux of R-134a is required to achieve the same heating rate as $\mathrm{R}-12$ due to the higher latent heat of vaporization of R-134a.

\section{R-113 in Round Tube and R-12 in Rectangular Channel}

To broaden the data base for small-channel two-phase flow pressure drop, the pressure drop results from flow boiling tests with R-113 (Wambsganss et al. 1993) were also included. Unlike R-134a and R-12, which have similar fluid physical properties, R-113 has a higher surface tension, higher liquid viscosity, higher liquid density, and lower gas density than those of R-12 and R-134a at the same saturation pressure or temperature. The two-phase flow pressure drop data of R-113 exhibit the same trends, with quality and mass flux, as in R-134a and R-12 (Tran 1998).

The hydraulic diameter of the rectangular channel used with R-12, was approximately equal to the diameter of the circular tube. A comparison of the test data from R-12 in round tube, with the data from R-12 in rectangular channel, showed no significant difference that would indicate a geometry effect. 


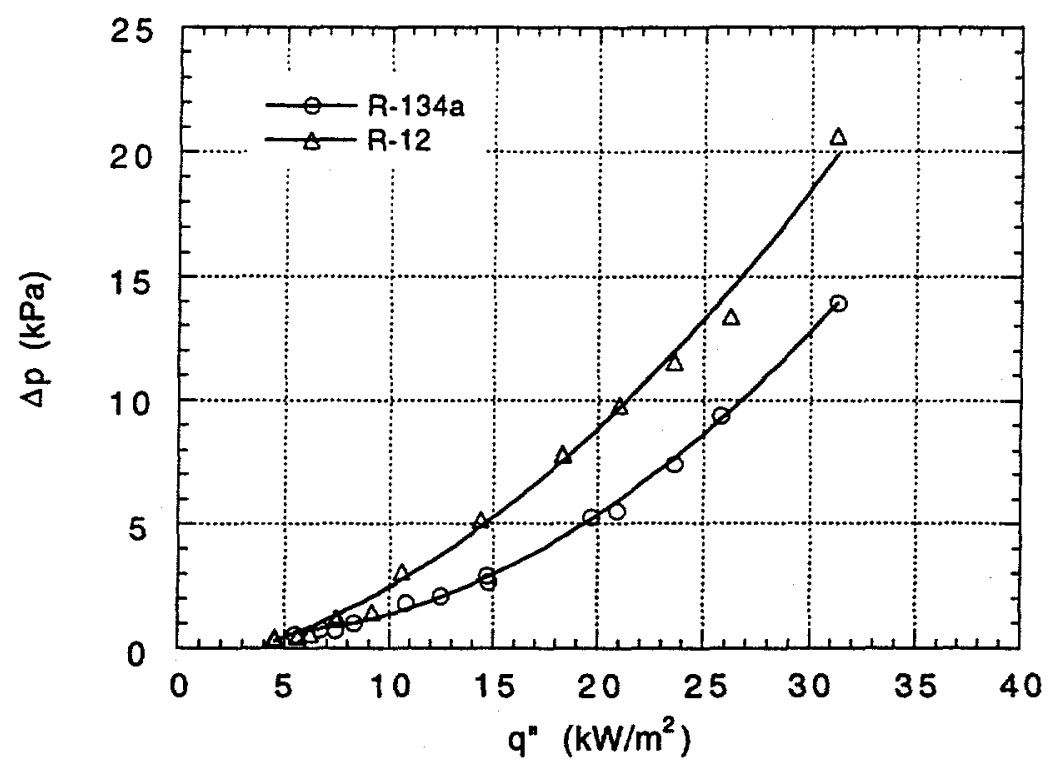

Fig. 6. Comparison of two-phase flow pressure drop between R-134a and $\mathrm{R}-12$ in terms of heat flux for $\mathrm{x}=0.7 \pm 0.05$ and $\mathrm{p}_{\mathrm{avg}}=835 \mathrm{kPa}$

\section{COMPARISON WITH LARGE TUBE CORRELATIONS}

The experimental data were compared with five state-of-the-art correlations for predicting two-phase frictional pressure drop in large tubes: (1) Friedel's correlation (Friedel 1979), (2) the B-coefficient method (Chisholm 1983), (3) the C-coefficient method (Chisholm 1983), (4) Jung and Radermacher correlation (Jung and Radermacher 1989), and (5) Souza and Pimenta correlation (Souza and Pimenta 1995). These correlations were developed specifically for large tubes with inside diameter of $8 \mathrm{~mm}$ or larger. The correlations of Jung and Radermacher and Souza and Pimenta were developed from refrigerant data. Tran (1998) summarizes the five correlations and presents detailed (i.e., function of quality) comparisons with the experimental data; a typical comparison plot is given in Fig. 7.

A careful review of the frictional two-phase flow pressure drop comparison between measured data and the five large-tube correlations led to the conclusions below (Tran 1998). At low mass flux, lower qualities, and certain pressures, some of the correlations satisfactorily predict experimental results, while the others significantly underpredict (as four of the correlations do in Fig. 7) or slightly overpredict the results. For all saturation pressures, none of the large-tube correlations satisfactorily predict the measured frictional two-phase flow pressure drop for mass flux $>150 \mathrm{~kg} / \mathrm{m}^{2} \mathrm{~s}$, and qualities larger than $\approx 0.6$. 


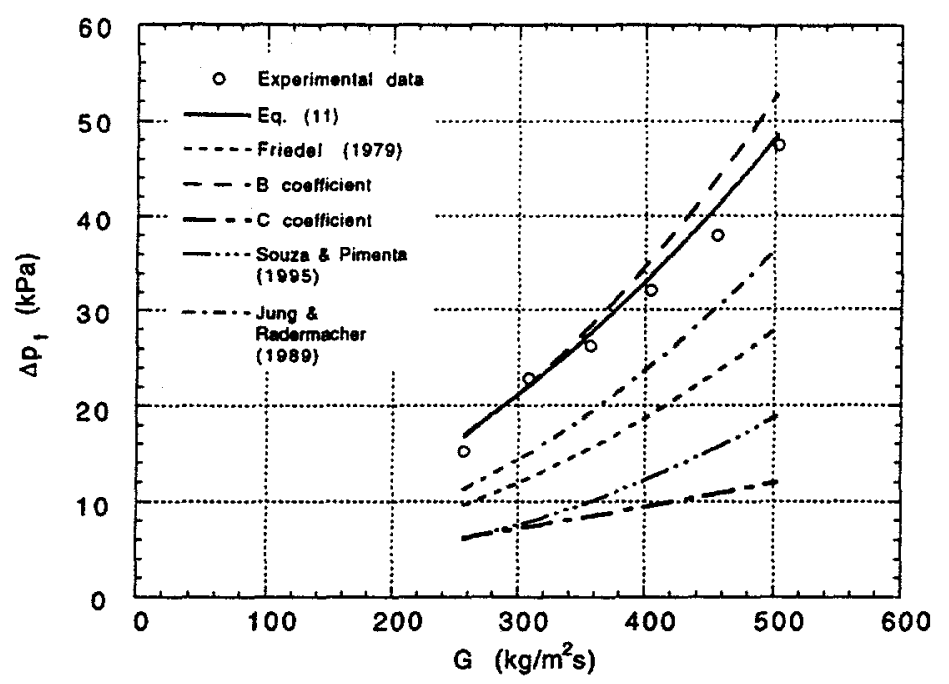

Fig. 7. Comparison of experimental data for R-134a at $\mathrm{p}_{\mathrm{avg}}=365 \mathrm{kPa}$, and $\mathrm{x}=$ $0.73 \pm 0.02$ with five large-tube correlations

We suggest that the reason why the large-tube correlations fail to predict small-channel response is related to the different flow behavior in small channels. The coalesced bubbles are confined, elongated, and slide over a thin liquid film as they flow downstream, compared to the flow boiling in a large tube where the bubbles grow and flow along the tubes going through different flow regimes without restriction. Therefore, it is reasonable to suggest that the greater pressure drop in a small channel may be due to additional friction related to the deformed/elongated bubble movement. Also, for the case of large tubes, the particular experiments of Souza and Pimenta (1995) showed a flow regime change from annular to mist at a quality of $\approx 0.85$, and the pressure drop reached a peak at this point. When the flow regime changes from annular to mist, the tube wall dries out, and the shear stress at the wall falls at a quality of $\approx 0.85$ due to a large viscosity ratio of 20 between the liquid refrigerant and its vapor (Souza and Pimenta 1995). Most of the large-tube correlations predict a much lower pressure drop at this point. However, the comparison in the present study shows that the decreased prediction of pressure drop using large-tube correlations starts at a lower quality of $\approx 0.6$, and the decrease is clearly evident at $x=0.73 \pm 0.02$ for all four pressures. This indicates that the largetube correlations cannot be used in predicting two-phase flow pressure drop in small channels for a quality $>0.6$. The present comparison also suggests that the transition from annular flow to mist flow regime did not occur in small channels until the quality is $>0.85$; in other words, the dryout point will be extended farther downstream than that in a large tube. 
PRESSURE DROP CORRELATION

In the following, a new pressure drop correlation is developed on the basis of Chisholm's Bcoefficient method (Chisholm 1983). For two-phase flow in a smooth tube, the B-coefficient is defined by

$$
\phi_{\mathrm{f} \ell \mathrm{o}}^{2}=1+\left(\Gamma^{2}-1\right)\left[\mathrm{Bx}^{0.875}(1-\mathrm{x})^{0.875}+\mathrm{x}^{1.75}\right] \text {, }
$$

where

$$
\Gamma^{2}=\frac{\left(\frac{d p}{d z}\right)_{f g o}}{\left(\frac{d p}{d z}\right)_{f \ell o}}
$$

The value of B is determined according to the criteria given in Table 2.

Table 2. Criteria for selecting B

\begin{tabular}{|c|c|c|}
\hline$\Gamma$ & $\mathrm{G}\left(\mathrm{kg} / \mathrm{m}^{2} \mathrm{~s}\right)$ & $\mathrm{B}$ \\
\hline \multirow{3}{*}{$\leq 9.5$} & $\leq 500$ & 4.8 \\
\cline { 2 - 3 } & $500<\mathrm{G}<1900$ & $2400 / \mathrm{G}$ \\
\cline { 2 - 3 } & $\geq 1900$ & $55 / \mathrm{G}^{0.5}$ \\
\hline \multirow{2}{*}{$9.5<\Gamma<28$} & $\leq 600$ & $520 /\left(\Gamma \mathrm{G}^{0.5}\right)$ \\
\cline { 2 - 3 } & $>600$ & $21 / \Gamma$ \\
\hline \multirow{2}{*}{$\geq 28$} & - & $\frac{15,000}{\Gamma^{2} \mathrm{G}^{0.5}}$ \\
\hline
\end{tabular}

The two-phase pressure drop over a quality range $\mathrm{x}=\mathrm{x}_{\mathrm{a}}$ to $\mathrm{x}=\mathrm{x}_{\mathrm{b}}$ can be calculated as

$$
\begin{aligned}
& \Delta \mathrm{p}_{\mathrm{f}}=\bar{\phi}_{\mathrm{f} \ell \mathrm{o}}^{2} \times \Delta \mathrm{p}_{\mathrm{f} \ell \mathrm{o}} \\
& \bar{\phi}_{\mathrm{f} \ell \mathrm{o}}^{2}=\frac{1}{\left(\mathrm{x}_{\mathrm{b}}-\mathrm{x}_{\mathrm{a}}\right)} \int_{\mathrm{x}_{\mathrm{a}}}^{\mathrm{x}_{\mathrm{b}}} \phi_{\mathrm{f} \ell \mathrm{o}}^{2}(\mathrm{x}) \mathrm{dx} .
\end{aligned}
$$


The B-coefficient method does not contain a parameter that accounts for the effect of tube dimension and fluid surface tension. Surface tension is expected to be an important fluid property that needs to be included in the two-phase flow pressure drop correlation, particularly for refrigerants. In the B-coefficient method, the pressure effect is reflected in the change of density and viscosity of the vapor and liquid phases. The size effect is included in the calculation of single-phase Fanning friction factor $f$, which relies on the Reynolds number as in the case of frictional pressure drop of single-phase flow. The complexity of two-phase flow, therefore, is not fully described, especially for small channels where the pressure drop is strongly influenced by the dynamics of the growing and flowing bubbles confined in a narrow space with a flowing liquid phase. Additional factors must be considered, including the effects of the interface between vapor and liquid phases, and the wetted surface between liquid and the channel wall.

In developing the new correlation, the definitions of $B$ and $\Gamma^{2}$ were modified to better reflect the physics of flow boiling in small tubes in which the channel size, fluid physical properties, mass flux, pressure, and quality are important factors. A new parameter related to $\Gamma^{2}$ is defined as

$$
\Psi^{2}=C \times \Gamma^{2}=C \frac{(d p / d z)_{f g o}}{(d p / d z)_{f \ell o}}
$$

The constant $\mathrm{C}$ in Eq. (5) is considered to be a scaling factor that represents the difference in pressure gradient between small tubes and large tubes.

A dimensionless number that can be used to substitute for the current B-coefficient was next sought. Cornwell and Kew (1993) proposed a dimensionless group called the "confinement number," expressed as

$$
\mathrm{N}_{\text {conf }}=\frac{\left[\frac{\sigma}{\mathrm{g}\left(\rho_{\ell}-\rho_{\mathrm{g}}\right)}\right]^{0.5}}{\mathrm{D}} .
$$

The numerator of this dimensionless parameter represents the ratio of surface tension force to buoyancy force, and D is the diameter of the channel. Cornwell and Kew (1993) and Kew and Cornwell (1995) performed boiling heat transfer tests with R-113 in a small channel, with gap size of 1 to $3 \mathrm{~mm}$, and reported that the confinement number correlated well with their heat transfer test results. However, in their published papers, they did not use the confinement number to correlate their two-phase flow pressure drop data. In our development of the new correlation, we used the confinement number as a substitute for the $\mathrm{B}$ coefficient, because the confinement number, $\mathrm{N}_{\text {conf }}$, includes surface tension and hydraulic diameter and can thus account for the maximum size of the bubble confined in small channel during a flow boiling process. The confinement number $\mathrm{N}_{\text {conf }}$, given by Eq. (6), also shows that a smaller channel gives a higher value of $\mathrm{N}_{\text {conf }}$, which leads to a higher pressure drop.

Including the scaling factor $\mathrm{C}$ as a multiplier on $\Gamma^{2}$, and using the confinement number $\mathrm{N}_{\text {conf }}$ to replace $B$, the new form is given as 


$$
\phi_{\mathrm{f} \ell \mathrm{o}}^{2}=1+\left(\mathrm{C} \Gamma^{2}-1\right)\left[\mathrm{N}_{\mathrm{conf}} \mathrm{x}^{0.875}(1-\mathrm{x})^{0.875}+\mathrm{x}^{1.75}\right] .
$$

In application, Eq. (7) is substituted into Eq. (4) and Eq. (4) is used with Eq. (3) to calculate pressure drop. The major difference between the proposed correlation and other correlations, such as the B-coefficient method (Chisholm 1983) and that of Souza and Pimenta (1995), is the distinction between flow regimes for the entire flow of liquid or gas flowing alone in the channel, and the use of the confinement number.

For the special case of saturated liquid at the entrance, which is the situation for the subject tests, $x=0$, the integrated result is

$$
\Delta \mathrm{p}_{\mathrm{f}}=\Delta \mathrm{p}_{\mathrm{f} \ell \mathrm{o}}\left\{1+\left(\mathrm{C} \Gamma^{2}-1\right)\left[\mathrm{N}_{\text {conf }} \mathrm{F}_{1}\left(\mathrm{x}_{\text {exit }}\right)+\mathrm{F}_{2}\left(\mathrm{x}_{\text {exit }}\right)\right]\right\}
$$

where

$$
\begin{aligned}
& F_{1}\left(x_{\text {exit }}\right)=0.0056+0.6466 x_{\text {exit }}-0.5343 x_{\text {exit }}^{2}+0.0888 x_{\text {exit }}^{3} \\
& F_{2}\left(x_{\text {exit }}\right)=\frac{\left(x_{\text {exit }}\right)^{1.75}}{2.75}
\end{aligned}
$$

The equation for $F_{1}$ (Eq. 9) was developed by curve-fitting calculated values from Chisholm (1983) over the range of $x_{0}=0$ to $x=x_{\text {exit. }}$. The equation for $F_{2}$ (Eq. 10) was obtained by direct integration.

Equation (8) was used in an optimization procedure to determine the value of the constant C. The optimization process was performed using a statistical analysis package, and was based on 610 data points of the three fluids; see Table 1. After the optimization process, the constant $\mathrm{C}$ in Eq. (5) was determined to be 4.3.

The new frictional two-phase multiplier can then be expressed as

$$
\bar{\phi}_{\text {f } \ell \mathrm{o}}^{2}=1+\left(4.3 \Gamma^{2}-1\right)\left[\mathrm{N}_{\mathrm{conf}} \mathrm{x}^{0.875}(1-\mathrm{x})^{0.875}+\mathrm{x}^{1.75}\right]
$$

where $\mathrm{N}_{\text {conf }}$ is given by Eq. (6).

Equation (11) is applicable for smooth tubes, for the refrigerants tested in the present study, and for pressure from 138 to $864 \mathrm{kPa}$, mass flux from 33 to $832 \mathrm{~kg} / \mathrm{m}^{2} \mathrm{~s}$, heat flux from 2.2 to $90.8 \mathrm{~kW} / \mathrm{m}^{2}$, and quality from 0 to 0.95 . In the final form of frictional two-phase multiplier (Eq. 11), the confinement number $\mathrm{N}_{\text {conf }}$ is the only parameter that accounts for fluid surface tension and the flow characteristic of two-phase flow boiling in small channels, where bubbles grow, coalesce into large bubbles, are elongated due to the size restriction of the small channel, and slide downstream, as reported by Kasza and Wambsganss (1995) and Kasza et al. (1997). Pressure drop calculated with the new frictional two-phase multiplier, Eq. (11), is compared with all experimental data in Fig. 8. 


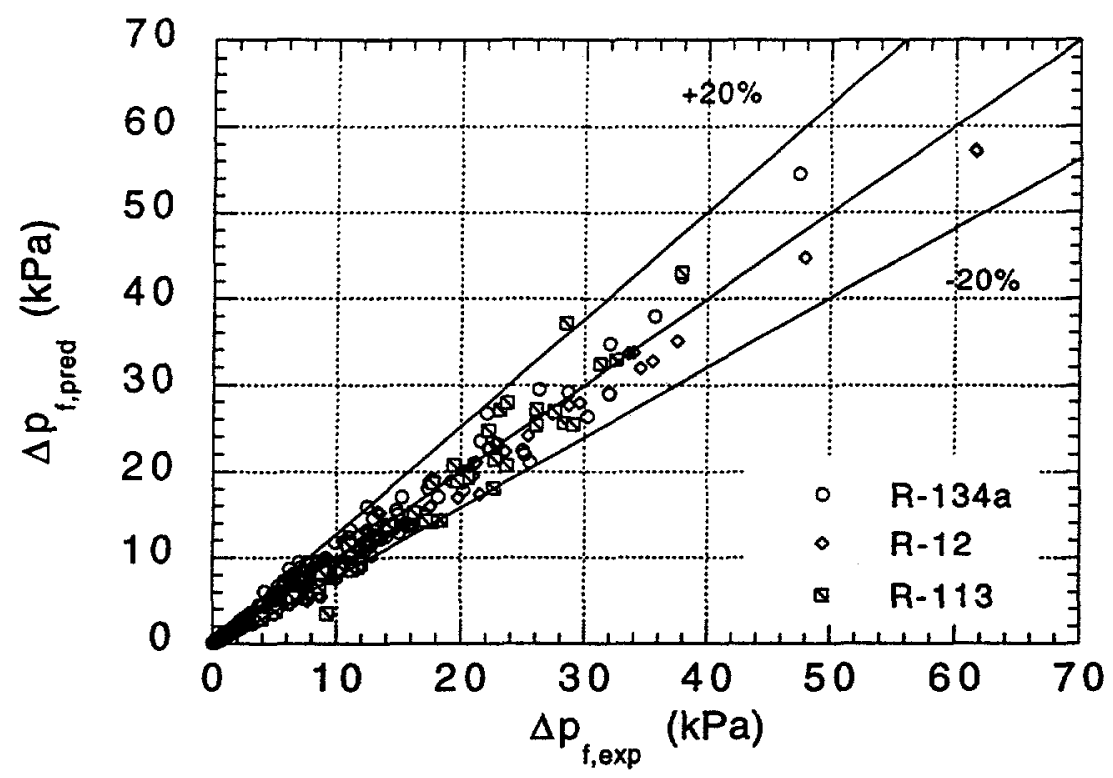

Fig. 8. Predicted frictional two-phase flow pressure drop using Eq. 11 vs. experimental frictional two-phase flow pressure drop data

A data analysis shows that most of the data are within $20 \%$ of error of prediction, and $93.8 \%$ of data are within $30 \%$. The proposed correlation has a mean deviation of $12.8 \%$ in predicting the frictional two-phase flow pressure drop. Predictions with Eq. (11) are compared with R-134a experimental data in Fig. 9. It is shown that Eq. (11) accurately predicts the frictional two-phase flow pressure drop of R-134a for all R-134a data at four pressures at the quality $\mathrm{x}=0.71 \pm 0.06$.

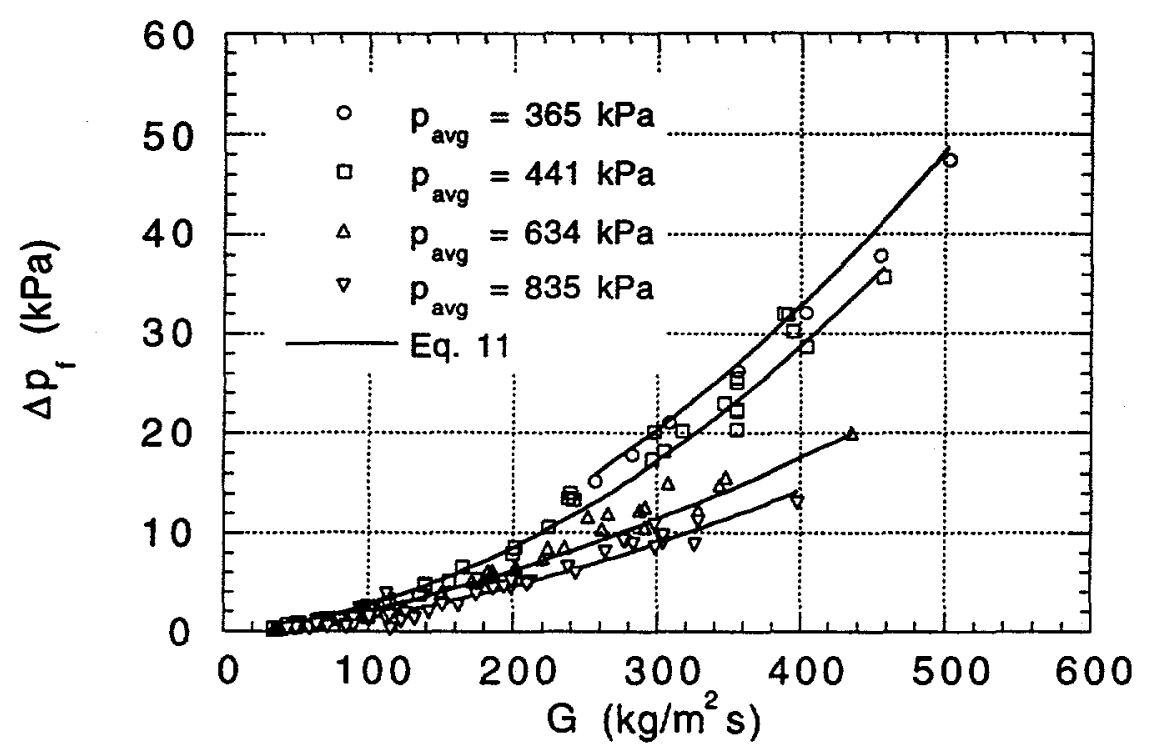

Fig. 9. Comparison between present correlation and experimental data of R-134a 


\section{CONCLUDING REMARKS}

- An experimental investigation of flow boiling of three refrigerants in small channels produced an extensive data base of two-phase pressure drop information.

- Pressure drop with R-134a was compared with R-12 on the basis of both similar mass flux and heating rate. In both cases, the trends were in reasonable agreement with those observed in comparisons with large-tube data.

- Five state-of-the-art large-tube correlations were evaluated, but they failed to predict the pressure drop of flow boiling in small channels for all test conditions.

- A new correlation for two-phase flow frictional pressure drop in small channels was developed on the basis of the B-coefficient method, taking into account the effects of surface tension and channel size. The new correlation is applicable for smooth tubes with hydraulic diameters of $\approx 3 \mathrm{~mm}$ for the three refrigerants tested.

\section{ACKNOWLEDGMENTS}

The research was supported by the U.S. Department of Energy, Office of Energy Efficiency and Renewable Energy, Office of Industrial Technologies, under Contract W-31-109Eng-38. The authors thank Roger Smith for his contributions in fabricating the test apparatus, instrumenting the test channel, and performing some of the tests; and Joyce Stephens for processing much of the data and preparing the figures and overall manuscript for publication.

\section{NOMENCLATURE}

$\begin{array}{ll}\text { B } & \text { Constant in B-coefficient method (Eq. 1) } \\ \mathrm{C} & \text { Constant (Eq. 3) } \\ \mathrm{D} & \text { Channel inside diameter }(\mathrm{m}) \\ \mathrm{D}_{\mathrm{h}} & \text { Channel hydraulic diameter }(\mathrm{m}) \\ \mathrm{dp} / \mathrm{dz} & \text { Pressure gradient along test section }(\mathrm{Pa} / \mathrm{m}) \\ \mathrm{G} & \text { Mass flux }\left(\mathrm{kg} / \mathrm{m}^{2} \mathrm{~s}\right) \\ \mathrm{g} & \text { Gravitational constant }\left(\mathrm{m} / \mathrm{s}^{2}\right) \\ \mathrm{N}_{\mathrm{conf}} & \text { Confinement number (Eq. } 6 \text { ) (dimensionless) } \\ \mathrm{p} & \text { Pressure }(\mathrm{Pa}) \\ \mathrm{P}_{\mathrm{r}} & \text { Reduced pressure }\left(=\mathrm{p} / \mathrm{p}_{\mathrm{cr}}\right) \\ \Delta \mathrm{p} & \text { Pressure drop }(\mathrm{Pa}) \\ \mathrm{q} & \left.\text { Heat flux (W/m } / \mathrm{m}^{2}\right) \\ \mathrm{Re} & \text { Reynolds number (dimensionless) } \\ \mathrm{x} & \text { Equilibrium mass quality } \\ \Gamma^{2} & \text { Physical property coefficient (Eq. 2) (dimensionless) } \\ \mu & \text { Viscosity }(\mathrm{kg} / \mathrm{m} \cdot \mathrm{s}) \\ \rho & \text { Density }\left(\mathrm{kg} / \mathrm{m}^{3}\right)\end{array}$




$\begin{array}{ll}\sigma & \text { Surface tension }(\mathrm{N} / \mathrm{m}) \\ \phi & \text { Two-phase multiplier (dimensionless) } \\ \bar{\phi} & \text { Averaged two-phase multiplier (dimensionless) } \\ \Psi & \text { Physical property index (Eq. } 5 \text { ) } \\ \text { Subscripts } \\ \text { avg } & \text { Averaged } \\ \mathrm{cr} & \text { Critical } \\ \text { exit } & \text { At the exit } \\ \mathrm{f} & \text { Due to friction } \\ \mathrm{g} & \text { Gas } \\ \text { go } & \text { Entire flow as gas only } \\ \ell & \text { Liquid } \\ \ell \text { o } & \text { Entire flow as liquid only } \\ \text { pred } & \text { Predicted }\end{array}$

\section{REFERENCES}

Chisholm, D., 1983, Two-Phase Flow in Pipelines and Heat Exchangers. New York: Longman Inc.

Cornwell, K., and Kew, P. A., 1993, "Boiling in Small Parallel Channels." in Energy Efficiency in Process Technology, ed. P. A. Pilavachi. New York: Elsevier, 624-638.

Eckels, S. J., and Pate, M. B., 1991, "Evaporation and Condensation of HCFC-134a and CFC-12 in a Smooth Tube and a Micro-Fin Tube." ASHRAE Trans., 97, Part 2, 71-81.

Eckels, S. J., Doerr, T. M., and Pate, M. B., 1994, "In-Tube Heat Transfer and Pressure Drop of R-134a and Ester Lubricant Mixtures in a Smooth Tube and a Micro-Fin Tube: Part IEvaporation." ASHRAE Trans., 100, Part 2, .

Friedel, L., 1979, "Improved Friction Pressure Drop Correlations for Horizontal and Vertical Two Phase Pipe Flow." Paper E2, European Two Phase Flow Group Meeting, Ispra, Italy.

Holman, J. P., and Gajda, W. J., Jr., 1978, Experimental Methods for Engineers, 3rd Ed. New York: McGraw-Hill, 44-45.

Jung, D. S., and Radermacher, R., 1989, "Prediction of Pressure Drop during Horizontal Annular Flow Boiling of Pure and Mixed Refrigerants." Int. J. Heat Mass Transfer, 32(12), 2435-2446.

Kasza, K. E., Didascalou, T., and Wambsganss, M. W., 1997, "Microscale Flow Visualization of Nucleate Boiling in Small Channels: Mechanisms Influencing Heat Transfer." in Proc. Conf. on Compact Heat Exchangers for the Process Industries, ed. R. K. Shah. New York: Begell House, Inc.

Kasza, K. E., and Wambsganss, M. W., 1995, "Flow Visualization of Microscale Thermal Mechanics of Boiling in Small Channels." in Flow Visualization VII - Proc. 7th International Symposium on Flow Visualization, ed. J. P. Crowder. New York: Begell House, Inc., 262-267.

Kew, P. A., and Cornwell, K., 1995, "Confined Bubble Flow and Boiling in Narrow Channels." 10th Int. Heat Transfer Conf., Brighton, U.K. 
Moffat, R. J., 1988, "Describing the Uncertainties in Experimental Results." Exp. Thermal Fluid Sci., 1, 3-17.

Souza, A. L., and Pimenta, M. M., 1995, "Prediction of Pressure Drop during Horizontal Two-Phase Flow of Pure and Mixed Refrigerants." in ASME Cavitation and Multiphase Flow Symposium. FED-Vol. 210, pp. 161-171.

Tran, T. N., 1998, "Pressure Drop and Heat Transfer Study of Two-Phase Flow in Small Channels." Ph.D. Dissertation, Texas Tech University, Lubbock, Texas.

Tran, T. N., Wambsganss, M. W., Chyu, M.-C., and France, D. M., 1997, "A Correlation for Nucleate Flow Boiling in Small Channels." in Compact Heat Exchangers for the Process Industries, ed. R. K. Shah. New York: Begell House, Inc., 353-363.

Tran, T. N., Wambsganss, M. W., and France, D. M., 1996, "Small Circular and Rectangular Channel Boiling with Two Refrigerants." Int. J. Multiphase Flow, 22(3), 485-498.

Wambsganss, M. W., Jendrzejczyk, J. A., and France, D. M., 1994, "Two-Phase Flow and Pressure Drop in Flow Passages of Compact Heat Exchangers." in Vehicle Thermal Management, SAE PT-46, ed. A. C. Alkidas. Warrendale, PA: Society of Automotive Engineers, 257-266.

Wambsganss, M. W., France, D. M., Jendrzejczyk, J. A., and Tran, T. N., 1993, "Boiling Heat Transfer in a Horizontal Small-Diameter Tube." ASME J. Heat Transfer, 115(4), 963-972; also, Argonne National Laboratory Report ANL-92/12 (1992). 